\title{
Correction to: Halophilic Prokaryotes in Urmia Salt Lake, a Hypersaline Environment in Iran
}

\author{
Fereshteh Jookar Kashi ${ }^{1} \cdot$ Parviz Owlia ${ }^{2} \cdot$ Mohammad Ali Amoozegar $^{3} \cdot$ Bahram Kazemi $^{4}$
}

Published online: 21 July 2021

๑) Springer Science+Business Media, LLC, part of Springer Nature 2021

\section{Correction to: Current Microbiology \\ https://doi.org/10.1007/s00284-021-02583-w}

The original version of this article unfortunately contain mistake in the co-authors affiliation. The co-authors affiliation has been updated.

Publisher's Note Springer Nature remains neutral with regard to jurisdictional claims in published maps and institutional affiliations.

The original article can be found online at https://doi.org/10.1007/ s00284-021-02583-w.

Fereshteh Jookar Kashi jookar@kashanu.ac.ir

1 Department of Cell and Molecular Biology, Faculty of Chemistry, University of Kashan, Kashan, Islamic Republic of Iran

2 Molecular Microbiology Research Center, Shahed University, Tehran, Iran

3 Department of Microbiology, School of Biology, College of Science, University of Tehran, Tehran, Iran

4 Department of Biotechnology, School of Advanced Technologies in Medicine, Shahid Beheshti University of Medical Sciences, Tehran, Iran 